\title{
Técnicas moleculares para la detección de cianobacterias en los embalses Riogrande II y La Fe, Colombia
}

\author{
Julio César Hurtado-Alarcón ${ }^{1}$ \& Jaime Polanía-Vorenberg ${ }^{2}$ \\ 1. Grupo BIODES-Biotecnología del Desarrollo Sustentable - Laboratorio de Biología Molecular y Celular, Universidad \\ Nacional de Colombia Sede Medellín, Calle 59A No 63-20 Bloque 19A-310 Medellín, Colombia; \\ jchurtad@unal.edu.co \\ 2. Posgrados en Bosques y Conservación Ambiental, Departamento de Ciencias Forestales, Universidad Nacional de \\ Colombia Sede Medellín; jhpolaniav@unal.edu.co
}

Recibido 03-IX-2012. Corregido 10-X-2013. Aceptado 13-XI-2013.

\begin{abstract}
Molecular techniques for cyanobacteria detection at Riogrande II and La Fe water reservoirs, Colombia. In lentic water bodies as reservoirs occur eutrophication processes, originated mainly from human activities (i.e. agriculture, animal exploitation). This influx of nutrients in aquatic ecosystems could promote blooms of potentially toxic cyanobacteria. The purpose of this work is to detect the presence of cyanobacteria strains in water samples, using molecular techniques to help in preventive management of reservoirs dedicated to water purification. We used two molecular techniques to detect genes implied with the synthesis of hepatotoxic microcystins from potentially toxic cyanobacteria strains, and to evaluate the molecular diversity of cyanobacteria in water samples from two high-mountain reservoirs used for purification of drinking water for the metropolitan area of Medellin, Colombia. Between 2010-2011 collections of 12 water samples were taken and DNA extraction together with PCR and DGGE analyses where carried out. We amplified 22 sequences between $250-300 \mathrm{bp}$ of the genes $m c y \mathrm{~A}$ and $m c y \mathrm{E}$, and these sequences were related with several strains and cyanobacteria genera accessions from NCBI-GenBank databases. Moreover, sequence amplifications of the $16 \mathrm{~S}$ small ribosomal RNA subunit - 16S rRNA- between 400-800bp were also performed in order to use them for the DGGE technique. The amplification products of DGGE were set in polyacrilamide gel with posterior denaturing electrophoresis, and the scanned images of the gel bands were analysed with the software GelCompar II. For Riogrande II and La Fe reservoirs we found 35 and 30 different DGGE bands, respectively, as a measurement of molecular diversity in these artificial ecosystems. Here, we demonstrated the utility of two molecular techniques for the detection of genes associated with toxicity and molecular diversity of cyanobacteria in reservoirs destined for drinking water in urban centers. We recommend strongly following with periodically molecular biology studies in these ecosystems combined with limnological and ecological data, as new tools for management of plants of water purification and for the prevention of potentially public health concerns. Rev. Biol. Trop. 62 (1): 403-419. Epub 2014 March 01.
\end{abstract}

Key words: eutrophication, cyanobacteria, toxicity, microcystins, diversity, molecular markers.

Medellín, en el Departamento de Antioquia, es la segunda ciudad más importante de Colombia. Su área metropolitana se encuentra distribuida a lo largo y ancho del Valle de Aburrá, y está conformada por los municipios de Medellín, Barbosa, Bello, Caldas, Copacabana, Envigado, Girardota, Itagüí, La Estrella y Sabaneta. Para el censo poblacional de 2005 en Colombia, se estimaron más de dos millones de habitantes en Medellín y cerca de un millón de habitantes en el resto de municipios del área metropolitana (DANE, 2005). Asimismo, algunos de estos municipios comparten la utilización de embalses para obtención de agua potable y energía eléctrica. En particular, parte del agua que abastece el acueducto de municipios del Valle de Aburrá como Medellín y Envigado, proviene principalmente de los embalses Riogrande II y La Fe, en los municipios de Don Matías y El Retiro, localizados 
al norte y al oriente de Medellín en el departamento de Antioquia, respectivamente.

Estudios anteriores han mostrado que embalses de características similares presentan procesos de eutrofización artificial, como consecuencia de actividades humanas (Ramírez, Gutiérrez \& Vargas, 2005). Tales actividades, particularmente las agrícolas, han incrementado la concentración de nutrientes y estimulado la productividad primaria en los cuerpos de agua continentales (Havens, James, East \& Smith, 2003). Este proceso de eutrofización artificial se manifiesta en floraciones visibles de plantas flotantes, agregaciones de macrófitas bénticas y, en algunos casos, en florecimientos de cianobacterias con potenciales efectos directos e indirectos sobre diferentes organismos, incluidos los seres humanos (Hitzfeld, Hoger \& Dietrich, 2000). Además de los nutrientes, la temperatura, el $\mathrm{pH}$ o las altas intensidades lumínicas también pueden influir sobre los florecimientos de cianobacterias (Runnegar, Kong \& Berndt, 1993; Dawson, 1998), con implicaciones directas e indirectas sobre los ecosistemas, puesto que estos microorganismos tienen la potencialidad de producir toxinas como estrategia de defensa. De esta forma, los peces, las aves y los seres humanos, entre otras formas de vida, pueden ser afectados por toxinas cianobacterianas -cianotoxinas- (Tencalla \& Dietrich, 1997; Azevedo et al., 2002). Autores como Azevedo \& Carmouze (1994), Codd, Steffensen, Burch, \& Baker (1994), Rodger, Turnbull, Edwards \& Codd (1994), entre otros, han registrado altas mortalidades de peces y animales domésticos expuestos a cianotoxinas. Por otra parte, en Caruarú, noreste del Brasil, fallecieron 76 pacientes de una clínica de hemodiálisis por contaminación del agua con la cianotoxina hepatotóxica microcistina-LR (Jochimsen et al., 1998; Domingos, Rubim, Molica, Azevedo \& Carmichael, 1999; Carmichael et al., 2001).

Para la detección de cianobacterias, el uso de técnicas de microscopía basada en su morfología ha sido una herramienta de uso común. No obstante, cianobacterias potencialmente tóxicas no tienen características morfométricas únicas que ayuden en su identificación (Ouellete, Handy \& Wilhelm, 2006). En algunos casos, las cepas tóxicas de géneros cianobacterianos se diferencian de las no tóxicas porque presentan genes que codifican para la síntesis de péptidos potencialmente tóxicos, los cuales pueden detectarse por métodos moleculares (Hotto, Satchwell \& Boyer, 2007). Uno de ellos, la Reacción en Cadena de la Polimerasa (PCR, Polymerase Chain Reaction), permite detectar genes del cluster mcy, algunos de los cuales codifican para proteínas del péptido hepatotóxico microcistina sintetasa (Hisbergues, Christiansen, Rouhiainen, Sivonen \& Börner, 2003). Dentro de este cluster, la detección de las regiones $m c y \mathrm{~A}$ y $m c y \mathrm{E}$ ha sido de particular importancia, puesto que son importantes en la identificación de géneros de cianobacterias potencialmente tóxicas (Rantala et al., 2006; Hotto et al., 2007). Así mismo, se han llevado a cabo diferentes estudios para analizar la ocurrencia natural de cianobacterias en ecosistemas acuáticos mediante la amplificación de secuencias de la subunidad $16 \mathrm{~S}$ del ADN ribosomal, lo cual es útil en el monitoreo de la distribución de especies (Matsunaga, Takeyama \& Nakayama, 2001), en estudios de biodiversidad (Ouellete et al., 2006), y en estudios filogenéticos y evolutivos (Genuário, Silva-Stenico, Welker, Moraesc \& Fiore, 2010).

Dado que la Organización Mundial de la Salud (WHO) permite un máximo de $1 \mu \mathrm{g} / \mathrm{L}$ de toxinas como microcistina-LR en agua para potabilizar (WHO, 2004), es de vital importancia detectar la presencia de cianobacterias con potencial toxicidad en cuerpos de agua lénticos dedicados a la obtención de agua potable para millones de personas. Considerando que Correa (2008) identificó dos géneros diferentes de cianobacterias productoras de MicrocistinaLR en el embalse Riogrande II, Colombia, mediante técnicas de microscopía tradicional, en este artículo se describe la detección molecular de cepas de cianobacterias con potencial toxicidad en los embalses Riogrande II y $\mathrm{La} \mathrm{Fe}$, Colombia, entre los años 2010-11, mediante la amplificación de los genes mcyA y $m c y$ E. Así mismo, se amplificó un fragmento de la 
subunidad 16S del ARN ribosomal (rRNA) cianobacteriano, y se realizó Electroforesis en Gradientes de Desnaturalización en Geles de poliacrilamida (DGGE), en un intento para detectar diferencias o similitudes en los patrones de bandeo obtenidos por esta técnica molecular con relación a los ecosistemas evaluados, como un estudio complementario para el monitoreo de la presencia de géneros y cepas de cianobacterias potencialmente tóxicas en estos ecosistemas artificiales en Colombia.

\section{MATERIALES Y MÉTODOS}

Área de estudio: Se obtuvieron muestras de agua de los embalses Riogrande II y La Fe, Colombia, en seis salidas de campo realizadas entre 2010-2011. El embalse Riogrande II se encuentra en la zona central del Departamento de Antioquia en jurisdicción de los municipios de San Pedro, Entrerríos, Belmira, Don Matías y Santa Rosa de Osos (Otaya, Vásquez \& Bustamante, 2008). Se construyó entre 19861988, y está formado por la confluencia de los ríos Chico y Grande, y la quebrada Las Ánimas; se encuentra a una altura promedio de $2270 \mathrm{msnm}$, y presenta un área superficial de $12000 \mathrm{~km}^{2}$, un volumen de $220 \mathrm{Mm}^{3}$, una profundidad máxima de $42 \mathrm{~m}$, una profundidad promedio de $37.9 \mathrm{~m}$ y una longitud máxima de 10km (Montoya \& Ramírez, 2007). El agua que se capta es aprovechada por las Empresas Públicas de Medellín -EPM- para el abastecimiento del acueducto de la ciudad y algunos municipios del Valle de Aburrá, y también es utilizada para la generación de energía en las centrales hidroeléctricas Tasajera y Niquía, generando alrededor de 324MW (CORANTIOQUIA, 1997). Por su parte, el embalse La Fe fue llenado en 1973 , y cubre un área de $173 \mathrm{~km}^{2}$. Se sitúa en el municipio de El Retiro, con alturas entre los 2 175-3 000msnm. Este embalse es utilizado principalmente para acueducto, pero una parte está destinada a recreación. De su volumen total (aprox. $15 \mathrm{Mm}^{3}$ ), $12 \mathrm{Mm}^{3}$ regulan el río Pantanillo, y $8 \mathrm{~m}^{3} / \mathrm{s}$ están destinados al acueducto metropolitano a través de la planta de tratamiento de La Ayurá, municipio de Envigado, Antioquia (Abuchaibe, Agudelo \& Sañudo 1988).

Recolecta de muestras de agua: Mediante redes de arrastre de fitoplancton de $35 \mu \mathrm{m}$ de diámetro de poro, se tomaron entre $100-300 \mathrm{~mL}$ de agua en la zona fótica en los embalses Riogrande II y La Fe. Dentro de cada embalse se tomaron muestras de agua en diferentes estaciones de muestreo (cuatro estaciones en

CUADRO 1

Estaciones de muestreo en los embalses Riogrande II y La Fe, Colombia

TABLE 1

Sampling sites in Riogrande II and La Fe reservoirs, Colombia

\begin{tabular}{|c|c|c|c|}
\hline Embalse & Estaciones & Nombre de la estación & Coordenadas \\
\hline \multirow[t]{4}{*}{ Riogrande II } & 1 & Entrada río Chico al embalse & $6^{\circ} 30^{\prime} 23.58^{\prime \prime} \mathrm{N}-75^{\circ} 32^{\prime} 9.483^{\prime \prime} \mathrm{W}$ \\
\hline & 2 & Confluencia quebrada Yerbabuena y río Chico & $6^{\circ} 30^{\prime} 34.128^{\prime \prime} \mathrm{N}-75^{\circ} 30^{\prime} 23.648^{\prime \prime} \mathrm{W}$ \\
\hline & 3 & Final brazo río Chico & $6^{\circ} 30^{\prime} 36.851^{\prime \prime N}-75^{\circ} 28^{\prime} 20.816^{\prime \prime} \mathrm{W}$ \\
\hline & 8 & $\begin{array}{l}\text { Confluencia río Grande, río Chico } \\
\text { y quebrada Las Animas }\end{array}$ & $6^{\circ} 30^{\prime} 51.344^{\prime \prime} \mathrm{N}-75^{\circ} 27^{\prime} 36.638^{\prime \prime} \mathrm{W}$ \\
\hline \multirow[t]{6}{*}{$\mathrm{La} \mathrm{Fe}$} & 1 & $\begin{array}{l}\text { Aguas abajo confluencia quebradas } \\
\text { Las Palmas y Espíritu Santo }\end{array}$ & $6^{\circ} 06^{\prime} 42.97^{\prime \prime} \mathrm{N}-75^{\circ} 29^{\prime} 48.59^{\prime \prime} \mathrm{W}$ \\
\hline & 2 & Sector Norte del embalse & $6^{\circ} 06^{\prime} 37.69^{\prime} \mathrm{N}-75^{\circ} 29^{\prime} 52.66^{\prime \prime} \mathrm{W}$ \\
\hline & 3 & Torre de captación & $6^{\circ} 06^{\prime} 24.41^{\prime \prime} \mathrm{N}-75^{\circ} 29^{\prime} 52.55^{\prime} \mathrm{W}$ \\
\hline & 4 & Confluencia quebradas Boquerón y San Luis & $6^{\circ} 06^{\prime} 13.95^{\prime \prime} \mathrm{N}-75^{\circ} 30^{\prime} 02.85^{\prime \prime} \mathrm{W}$ \\
\hline & 6 & Antes de la presa del embalse & $6^{\circ} 05^{\prime} 55.04^{\prime \prime} \mathrm{N}-75^{\circ} 29^{\prime} 25.40^{\prime \prime} \mathrm{W}$ \\
\hline & 7 & Sector sur-occidente del embalse & $6^{\circ} 05^{\prime} 57.97^{\prime \prime} \mathrm{N}-75^{\circ} 29^{\prime} 48.12^{\prime \prime} \mathrm{W}$ \\
\hline
\end{tabular}


Riogrande II: 1, 2, 3, 8; y seis estaciones en La Fe: 1, 2, 3, 4, 6, 7), las cuales aparecen con sus nombres sintetizados y coordenadas geográficas en el cuadro 1.

Las muestras de agua se pasaron por filtros de celulosa de $0.5 \mu \mathrm{m}$ y se refrigeraron a $4^{\circ} \mathrm{C}$ hasta la noche o hasta el día siguiente en el laboratorio del grupo GAIA -Grupo de Investigación, Gestión y Modelación Ambiental-, en la Sede de Investigación Universitaria de la Universidad de Antioquia, SIU. Posteriormente, se transportaron hacia el Laboratorio de Biología Molecular y Celular de la Universidad Nacional de Colombia, Sede Medellín. Allí, las muestras se homogenizaron y de cada una de ellas se tomaron volúmenes de $50 \mathrm{~mL}$ por duplicado, y se centrifugaron en volúmenes decrecientes de 50,15 , y $2 \mathrm{~mL}$ entre $200-3000 \mathrm{~g}$ durante $10-15 \mathrm{~min}$. De esta forma, el precipitado depositado en los viales de menor volumen $(2 \mathrm{~mL})$, contenía la materia prima para llevar a cabo las extracciones de ADN, las cuales se realizaron usando el estuche QIAamp DNA Mini Kit (Qiagen), de acuerdo con las recomendaciones del fabricante. $\mathrm{La}$ concentración y pureza del ADN extraído se evaluó mediante un espectrofotómetro Nanodrop (Thermoscientific, USA). La calidad de las extracciones de ADN se verificó en geles de agarosa al $1.0 \%$ teñidos con bromuro de etidio

$(\mathrm{EtBr})(10 \mathrm{mg} / \mathrm{mL})$, y fueron visualizadas en transiluminador de luz ultravioleta.

Amplificación por PCR (Polymerase Chain Reaction, Reacción en Cadena de la Polimerasa) de regiones de interés: Inicialmente, se evaluaron las secuencias cebadoras $c p c B-c p c A$ (PC $\beta-\mathrm{F}$ :

5>-GGCTGCTTGTTTACGCGACA-3>, y PC $\alpha-R:$ 5>-CCAGTACCACCAGCAACTAA-3> (Neilan, Jacobs \& Goodman, 1995), para amplificar el gen que codifica para ficocianina-c específica de cianobacterias (Cuadro 2 ), como control positivo de la presencia de cianobacterias en las muestras de ADN obtenidas de los embalses. Para la amplificación posterior de fragmentos del cluster de genes mcy y de la región $16 \mathrm{~S}$ del ARN ribosomal, solo se utilizaron muestras de ADN positivas para ficocianina-c.

\begin{tabular}{|c|}
\hline $\begin{array}{l}\text { Evaluación de genes } \\
\text { los con toxicidad de } \\
\text { cianobac- } \\
\text { as: Para identificar }\end{array}$ \\
\hline
\end{tabular}

CUADRO 2

Cebadores usados en la amplificación por PCR de regiones de ADN asociadas con ficocianina y con toxicidad de cianobacterias en los embalses Riogrande II y $\mathrm{La} \mathrm{Fe}$

TABLE 2

Primers used in PCR amplification of DNA regions of cyanobacteria phycocianin and toxicity genes from Riogrande II and La Fe reservoirs

\begin{tabular}{|c|c|c|c|c|}
\hline $\begin{array}{l}\text { Nombre } \\
\text { cebador }\end{array}$ & Secuencia & $\begin{array}{l}\text { Gen o región } \\
\text { a amplificar }\end{array}$ & $\begin{array}{l}\text { Tamaño } \\
\text { región }(\mathrm{pb})^{*}\end{array}$ & Ref. \\
\hline $\begin{array}{l}c p c B-c p c A \\
\mathrm{PC} \beta-\mathrm{F} \\
\mathrm{PC} \alpha-\mathrm{R}\end{array}$ & $\begin{array}{l}\text { 5'-GGCTGCTTGTTTACGCGACA-3', } \\
\text { 5'-CCAGTACCACCAGCAACTAA-3', }\end{array}$ & $\begin{array}{l}\text { Subunidades } \alpha \text { y } \beta \text {, región } \\
\text { IGS del operon ficoianina }\end{array}$ & $\sim 700$ & $\begin{array}{l}\text { Neilan et al. } \\
\quad(1995)\end{array}$ \\
\hline mcyA Cd & $\begin{array}{l}\text { 1F 5'-AAAATTAAAAGCCGTATCAAA-3' } \\
\text { 1R 5'-AAAAGTGTTTTATTAGCGGCTCAT }\end{array}$ & $\begin{array}{l}\text { Gen } m c y \text { A del cluster de } \\
\text { genes } m c y\end{array}$ & $\sim 300$ & $\begin{array}{l}\text { Hisbergues et al. } \\
\text { (2003) }\end{array}$ \\
\hline $\begin{array}{l}\text { mcyE-F2 } \\
\text { mcyE-R8 } \\
\text { mcyE-12R }\end{array}$ & $\begin{array}{l}\text { 5'-GAAATTTGTGTAGAAGGTGC-3' } \\
\text { 5'- CAATGGGAGCATAACGAG -3' } \\
\text { 5'-CAATCTCGGTATAGCGGC-3' }\end{array}$ & $\begin{array}{l}\text { Gen } m c y \mathrm{E} \text { del cluster de } \\
\text { genes mcy en Microcystis y } \\
\text { Anabaena }\end{array}$ & $300-500$ & $\begin{array}{l}\text { Vaitomaa et al. } \\
\qquad(2003)\end{array}$ \\
\hline
\end{tabular}

$*$ = Pares de bases. 
se evaluaron cebadores específicos (mcyE-F2: 5'-GAAATTTGTGTAGAAGGTGC-3' para ambos géneros; mcyE-R8 5'- CAATGGGAGCATAACGAG-3', Microcystis; mcyE-12R 5'-CAATCTCGGTATAGCGGC-3', Anabaena) (Vaitomaa et al., 2003; Rantala et al., 2006; Hotto et al., 2007) (Cuadro 2).

El volumen final de cada mezcla de PCR fue de $25 \mathrm{~mL}$. Las amplificaciones por PCR de las regiones de interés se realizaron de acuerdo con los protocolos publicados por Hisbergues et al. (2003) (gen mcyA), Vaitomaa et al. (2003) (gen $m c y \mathrm{E}$ ) y Dos Anjos et al. (2006) (operon ficocianina cianobacteriana, $c p c B-c p c A$ ), con respecto a concentraciones de reactivos y perfiles térmicos. Las reacciones de PCR se llevaron a cabo en un termociclador T3 000 (Biometra, Alemania) en microtubos de $200 \mu \mathrm{L}$. Los productos de amplificación se visualizaron mediante electroforesis en geles de agarosa $(1.5 \%)$ teñidos con $\operatorname{EtBr}(10 \mathrm{mg} / \mathrm{mL})$. Las condiciones de corrido fueron: 60-80min en solución 1X TBE (Tris-ácido bórico-EDTA, pH8.0), a un voltaje constante (80V) en cámaras de electroforesis horizontales (Bio-Rad, E.U.A.). Los geles de agarosa se observaron sobre una pantalla de luz ultravioleta y se fotografiaron con un equipo para captura de imágenes (Biometra, Alemania) para confirmar la efectividad de la amplificación. Para determinar los tamaños de los alelos en cada corrida se insertó un marcador molecular de secuencia conocida en un rango de 100-1 000 pares de bases (GeneRuler Low Range DNA Ladder, Fermentas, Canada) (Hisbergues et al., 2003, Dos Anjos et al., 2006).

Purificación de las muestras positivas y secuenciación: Las muestras que resultaron positivas para genes de toxicidad $(m c y \mathrm{~A}, m c y \mathrm{E})$ se purificaron utilizando el estuche comercial QIAquick PCR Purification Kit (QIAGEN, Alemania), siguiendo las recomendaciones del fabricante, las amplificaciones se verificaron en geles de agarosa (1.5\%) y finalmente se enviaron a secuenciar (Macrogen, Corea). Se realizaron comparaciones individuales de las secuencias obtenidas de los genes mcyA y $m c y \mathrm{E}$ en las bases de datos del NCBI (National Center for Biotechnology Information, Centro Nacional de Información en Biotecnología, E.U.A.), usando la herramienta para alineamientos locales BLAST (Basic Local Alignment Search Tool).

Análisis de secuencias para los genes mcyA y $\boldsymbol{m} \boldsymbol{c y E} \mathbf{E}$ : Se utilizó el editor de alineamientos gratuito BioEdit (Biological Sequence Alignment Editor) versión 7.0.9 (Hall, T.A. 1999), el cual se puede descargar gratuitamente en el sitio URL http://www.mbio.ncsu. edu/bioedit/bioedit.html. Este programa permite obtener secuencias consenso a partir de los resultados de las secuenciaciones de las cadenas Forward y Reverse de cada una de las muestras positivas para los genes mcyA y $m c y$ E. Con las secuencias consenso, se realizó un alineamiento múltiple con el algoritmo Clustal W incluido en el programa de uso libre BioEdit. Adicionalmente, las secuencias consenso obtenidas fueron alineadas y analizadas junto con secuencias publicadas en las bases de datos del NCBI de algunos géneros y cepas de cianobacterias (Microcystis sp., Nostoc sp., Anabaena sp., Radiocystis sp.) que portan los genes $m c y \mathrm{~A}$ y $m c y \mathrm{E}$, relacionados con la síntesis de péptidos con potencial hepatotoxicidad (Cuadro 3). La escogencia del modelo de sustitución nucleotídica y los análisis de agrupamiento de las secuencias se llevaron a cabo con el programa de uso libre MEGA5, descargado del sitio URL http://www.megasoftware.net/ (Tamura et al., 2011).

Amplificación de secuencias de la subu-
nidad 16S del ARN ribosomal (rRNA) para
la evaluación de diversidad de cepas de
cianobacterias mediante la técnica mole-
cular DGGE (Denaturing gradient gel
electrophoresis - Electroforesis en gel con
gradiente de desnaturalización): Se evalua-
ron las secuencias cebadoras descritas por
Nübel, Garcia-Pichel \& Muyzer (1997), para
amplificar regiones del gen que codifica para
la subunidad 16S rRNA de cianobacterias
(Cuadro 3), de aproximadamente 422 pares de


CUADRO 3

Nombre de las accesiones de cepas o géneros cianobacterianos, descargados del sitio web del NCBI-GenBank, para su uso en los alineamientos de secuencias de los genes mcyA y mcyE, en los embalses Riogrande II y La Fe, Colombia

TABLE 3

Cyanobacterial strains accession numbers downloaded from NCBI-GenBank web site, used for the alignment of $m c y$ A and $m c y \mathrm{E}$ gene sequences, from Riogrande II and La Fe reservoirs in Colombia

\begin{tabular}{|c|c|c|c|c|c|}
\hline Cepa o género & $\begin{array}{l}\mathrm{N}^{\circ} \text { accesión } \\
\text { GenBank }\end{array}$ & Gen & $\begin{array}{c}\text { Tamaño } \\
\text { secuencia }(\mathrm{pb})^{*}\end{array}$ & Localidad & Referencia \\
\hline Anabaena sp. BIR259 & HM104625.1 & $m c y \mathrm{~A}$ & 189 & Mar Báltico, Europa & Fewer et al. (2011) \\
\hline Microcystis sp. M124FF01 & FJ469467.1 & $m c y \mathrm{~A}$ & 246 & California, E.U.A. & $\begin{array}{l}\text { Moisander et al. } \\
\text { (2009). }\end{array}$ \\
\hline $\begin{array}{l}\text { Uncultured bacterium clone } \\
\text { M1089FF01 }\end{array}$ & FJ469466.1 & $m c y \mathrm{~A}$ & 246 & California, E.U.A. & $\begin{array}{l}\text { Moisander et al. } \\
\text { (2009). }\end{array}$ \\
\hline $\begin{array}{l}\text { Uncultured bacterium clone } \\
\text { M502FF01 }\end{array}$ & FJ469446.1 & $m c y \mathrm{~A}$ & 252 & California, E.U.A. & $\begin{array}{l}\text { Moisander et al. } \\
\text { (2009). }\end{array}$ \\
\hline $\begin{array}{l}\text { Uncultured bacterium clone } \\
\text { M201FF02 }\end{array}$ & FJ469431.1 & $m c y \mathrm{~A}$ & 252 & California, E.U.A. & $\begin{array}{l}\text { Moisander et al. } \\
\text { (2009). }\end{array}$ \\
\hline Radiocystis fernandoi SPC 736 & FJ807671.1 & $m c y \mathrm{~A}$ & 162 & Sao Paulo, Brasil & Lorenzi et al. (s.f.) \\
\hline Anabaena sp. BIR256 & EF565281.1 & $m c y \mathrm{E}$ & 781 & Mar Báltico, Europa & Fewer et al. (2011) \\
\hline $\begin{array}{l}\text { Uncultured Nostoc sp. clone } \\
\text { K S45 }\end{array}$ & JQ007857.1 & $m c y \mathrm{E}$ & 906 & $\begin{array}{c}\text { East Perthshire, } \\
\text { Escocia }\end{array}$ & $\begin{array}{l}\text { Kaasalainen et al. } \\
\text { (2012) }\end{array}$ \\
\hline Microcystis aeruginosa $\mathrm{BR} 12$ & GU817049.1 & $m c y \mathrm{E}$ & 470 & Sharypovo, Rusia & Gaevsky et al. (2011) \\
\hline Nostoc sp. 74.2 & JF342717.1 & $m c y \mathrm{E}$ & 412 & Australia & $\begin{array}{l}\text { Gehringer et al. } \\
\text { (2012) }\end{array}$ \\
\hline
\end{tabular}

bases (bp) (cebadores 359F-781R), a partir del ADN extraído de las muestras de agua de los embalses Riogrande II y La Fe (Cuadro 4). Se utilizó el cebador Forward 359F modificado en el extremo 3', mediante la adición de 40 desoxirribonucleótidos fosfato guanina-citosina (GC), para modificar el comportamiento desnaturalizante del fragmento de interés y mejorar la resolución de los fragmentos de tamaño similar pero con contenido diferente de
GC (Muyzer, De Waal \& Uitterlinden, 1993). La mezcla de PCR se preparó de acuerdo con lo publicado por Nübel et al. (1997). Se tomaron $25 \rho \mathrm{m}$ de cada primer, $25 \eta \mathrm{mol}$ dNTPs, $10 \mathrm{~mL}$ buffer PCR, $(100 \mathrm{mM}$ Tris- $\mathrm{HCl}[\mathrm{pH}$ $9.0], 1.5 \mathrm{mM} \mathrm{MgCl}, 500 \mathrm{mM} \mathrm{KCl}), 0.5 \mathrm{U}$ Taq polimerasa (FERMENTAS UAB, Canadá) y

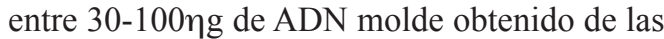
extracciones, en un volumen final de $30-50 \mathrm{~mL}$ por reacción. El perfil térmico de la PCR

\section{CUADRO 4}

Cebadores evaluados para amplificación por PCR y DGGE de la región 16S rRNA en muestras de agua de los embalses Riogrande II y La Fe en 2010-11

TABLE 4

Primers used in PCR amplification and DGGE of 16S rRNA gene in water samples from Riogrande II and La Fe reservoirs, Colombia

\begin{tabular}{llc}
\multicolumn{1}{c}{ Cebador } & \multicolumn{1}{c}{ Secuencia $\left(5^{\prime}{ }^{\prime}-3^{\prime}\right)$} & Sitio blanco $(\mathrm{pb})$ \\
CYA359F & GGG GAA TYT TCC GCA ATG GG & $359-378$ \\
CYA781R(a) & GAC TAC TGG GGT ATC TAA TCC CAT T & $781-805$ \\
CYA781R(b) & GAC TAC AGG GGT ATC TAA TCC CTT T & $781-805$ \\
\hline
\end{tabular}

\footnotetext{
* = Pares de bases.
} 
incluyó un ciclo inicial de desnaturalización del $\mathrm{ADN}$ a $95^{\circ} \mathrm{C}$, seguido de 35 ciclos de un minuto cada uno a $94^{\circ} \mathrm{C}, 60^{\circ} \mathrm{C}$ y $72^{\circ} \mathrm{C}$. Por último, se incluyó un ciclo de extensión final a $72^{\circ} \mathrm{C}$ por $10 \mathrm{~min}$.

Evaluación de la técnica DGGE: Las muestras que amplificaron con los cebadores $359 \mathrm{~F}_{\mathrm{GC}}-781 \mathrm{R}$ se precipitaron con etanol de grado reactivo al 96\%, se llevaron a una concentración entre $2000-3000 \eta$ g y se diluyeron en un volumen final de $10 \mu \mathrm{L}$ con agua ultrapura estéril. Con estos productos de PCR se llevaron a cabo electroforesis en geles de poliacrilamida, en el sistema D-Code Mutation Detection System (Bio-Rad, E.U.A.). Para ello, se prepararon geles de poliacrilamida al $8 \%$ y $1 \mathrm{~mm}$ de grosor, en dos gradientes desnaturalizantes de urea y formamida (30-60\%), de acuerdo con los protocolos descritos por Nübel et al. (1997). Los geles de poliacrilamida se sometieron a electroforesis en solución tampón TAE (40mM Tris-HCl [pH 8.3], 20mM ácido acético, $1 \mathrm{mM}$ EDTA), durante 3.5 horas a $200 \mathrm{~V}$, a una temperatura constante de $60^{\circ} \mathrm{C}$. Los geles de poliacrilamida se tiñeron con nitrato de plata $\left(\mathrm{AgNO}_{3}\right)$ y se sumergieron en solución reveladora $(\mathrm{NaOH}$, formamida y agua destilada) para visualizar bandas de ADN, (Sanguinetti, Dias Neto \& Simpson, 1994). Posteriormente, los geles se fijaron con solución Etanol-ácido acético 95:5, se escanearon y se digitalizaron para el análisis de imágenes usando el programa GelCompar II 6.0 (Applied Maths, Bélgica). Este programa permite analizar agrupaciones (clusters) evaluando algoritmos para determinación de similitud de bandas de amplificaciones y polimorfismos en evaluaciones de diversidad molecular (Rademaker \& de Bruijin, 2004). Dicha metodología es útil para evaluar similitudes o diferencias en los patrones de bandeo de las amplificaciones de la región 16S del ARN ribosomal cianobacteriano, obtenidos en ecosistemas lénticos artificiales e independientes como lo son los embalses Riogrande II y La Fe.

Por medio del programa GelCompar II 6.0, se calculó la matriz de distancia basada en las bandas de DGGE usando el coeficiente de similitud de Dice (Nei \& Li, 1979), el cual es comúnmente usado para comparar especies entre ecosistemas diferentes. Dos perfiles idénticos dan como resultado un valor igual al $100 \%$, mientras que dos perfiles completamente diferentes dan un valor igual al $0 \%$. Se realizó un análisis de agrupamiento mediante el método de promedio aritmético no ponderado (UPGMA -Unweighted Pair Group Method using Arithmetic averages), y los resultados fueron presentados finalmente como un dendrograma.

\section{RESULTADOS}

Extracción y cuantificación de ADN a partir de las muestras de agua tomadas en los embalses Riogrande II y La Fe: El trabajo de extracción de ADN usando el estuche comercial permitió obtener ADN de buena calidad en las muestras de agua obtenidas de los embalses Riogrande II y La Fe, Colombia. Así mismo, la cuantificación del ADN usando espectrofotómetro arrojó lecturas entre 7.3$188.3 \eta \mathrm{g} / \mathrm{mL}$. A partir de las muestras cuantificadas, se usaron concentraciones de $20 \eta \mathrm{g}$ de ADN por cada muestra para las amplificaciones por PCR de las regiones de interés.

Amplificaciones de genes del cluster $m c y$, relacionados con toxicidad de cianobacterias:

Amplificación de los genes mcyA y mcyE: Para los dos embalses evaluados, se obtuvieron amplificaciones en las reacciones de PCR de los genes mcyA y mcyE en las muestras de agua obtenidas. Las amplificaciones de parte del dominio de condensación $(\mathrm{Cd})$ del gen $m c y A$, tuvieron un tamaño aproximado al publicado por Hisbergues et al. (2003) de $300 \mathrm{bp}$, utilizando el par de cebadores $m c y A-\mathrm{Cd}$ (Hisbergues et al., 2003). Para el gen $m c y E$, solo se obtuvieron amplificaciones por PCR con los cebadores específicos para Microcystis sp. (mic-mcyE R8). El tamaño obtenido para esta región fue diferente a lo encontrado por otros autores (aprox. 300bp) (Vaitomaa et al., 
2003). Para Anabaena sp. no se obtuvieron amplificaciones positivas al usar los cebadores Ana-mcyE 12R.

Comparación de las secuencias consenso obtenidas por secuenciación de las amplificaciones de los genes $m c y A$ y $m c y E$, usando la herramienta de alineamiento local BLAST: Para el gen mcyA que codifica para microcistina sintetasa, se hallaron correspondencias en el GenBank con varios clones para los embalses evaluados. Para el embalse Riogrande II, las consensos analizados correspondieron con un clon de cianobacterias sin identificar (Uncultured cyanobacterium clone 03LO-OS4, $\mathrm{N}^{\circ}$ accesión GenBank EF424345.1, cobertura 99\%) y con un clon no cultivado de Microcystis (Uncultured Microcystis sp. clone MB20, $\mathrm{N}^{\mathrm{o}}$ accesión GenBank JN108773.1, cobertura $100 \%$ ). Para el embalse La Fe, de cuatro consensos dos se relacionaron con clones no cultivados de cianobacterias sin identificar, y dos consensos se relacionaron con uno de los clones hallados en el embalse Riogrande II (Uncultured cyanobacterium clone 03LO-OS4, $\mathrm{N}^{\circ}$ accesión GenBank EF424345.1, cobertura 99\%; Uncultured cyanobacterium clone 03LOOR9, $\mathrm{N}^{\mathrm{o}}$ accesión GenBank EF424337.1, cobertura $100 \%$ ).

Con relación al gen $m c y \mathrm{E}$ que codifica para microcistina sintetasa para ambos embalses, se hallaron correspondencias similares. Para los embalses Riogrande II y $\mathrm{La} \mathrm{Fe}$, todos los 13 consensos diferentes se relacionaron con las mismas cepas de Microcystis (Microcystis sp. CYN06, No accesión GenBank FJ393327.1, cobertura $99-100 \%$ ), y en una medida similar con una cepa de Microcystis aeruginosa (CPCC 299, $\mathrm{N}^{\mathrm{o}}$ accesión GenBank JN936964.1, cobertura $99-100 \%$, identidad $>98 \%$ ). No obstante para el embalse $\mathrm{La} \mathrm{Fe}$, de dos secuencias consenso, una de ellas tuvo altos valores de identidad $(98 \%)$ pero con un valor bajo de cobertura de $44 \%$.

Análisis de agrupamiento para las secuencias consenso obtenidas: El programa BioEdit, permitió encontrar siete secuencias consenso para el gen mcyA y 13 secuencias consenso para el gen $m c y \mathrm{E}$. El programa MEGA 5 permitió obtener matrices de agrupamiento y de distancias genéticas para estos genes. Los análisis de las secuencias consenso de los genes mcyA y $m c y \mathrm{E}$ se basaron en el método de Máxima Verosimilitud (Maximum-likelihood, ML) usando el modelo de sustitución nucleotídica Kimura 2P (K2), y se obtuvieron dendrogramas de agrupamiento (Fig. 1 y Fig. 2), con topologías soportadas por análisis de Bootstrapping (1 000 réplicas). Las secuencias que se obtuvieron de las bases de datos del NCBI de algunos géneros y cepas de cianobacterias (Microcystis sp., Nostoc sp., Anabaena sp., Radiocystis sp.), se mostraron como outgroups para las secuencias obtenidas en el presente estudio, debido a altos valores de remuestreo mediante bootstrapping hallados entre los clados obtenidos (99\%), exceptuando una secuencia obtenida del embalse La Fe para el gen mcyA.

Para el gen mcyA se encontraron dos agrupaciones de secuencias, la primera que comprende ocho de las nueve secuencias de los embalses Riogrande II y La Fe, y la segunda agrupación la cual incluye seis secuencias del NCBI más una sola secuencia del embalse La Fe. Para este gen, los valores de remuestreo bootstrapping entre la mayoría de las secuencias de los embalses antioqueños fueron muy bajos (1-11\% de las replicaciones del remuestreo). Los valores de bootstrapping para la segunda agrupación de secuencias (una secuencia del embalse La Fe y las secuencias obtenidas del NCBI), fueron mayores a los valores obtenidos para la primera agrupación (41-99\% de las replicaciones del remuestreo), siendo el valor más bajo (41\%) el obtenido al comparar cinco de las seis muestras del NCBI con la secuencia del embalse La Fe.

Para el gen $m c y \mathrm{E}$, se hallaron varias agrupaciones dentro de las muestras de los embalses evaluados, separando claramente dichas muestras de las secuencias obtenidas del NCBI para el gen $m c y \mathrm{E}$. Los valores obtenidos de remuestreo mediante bootstrapping fueron muy bajos para 11 de las 13 secuencias de los 


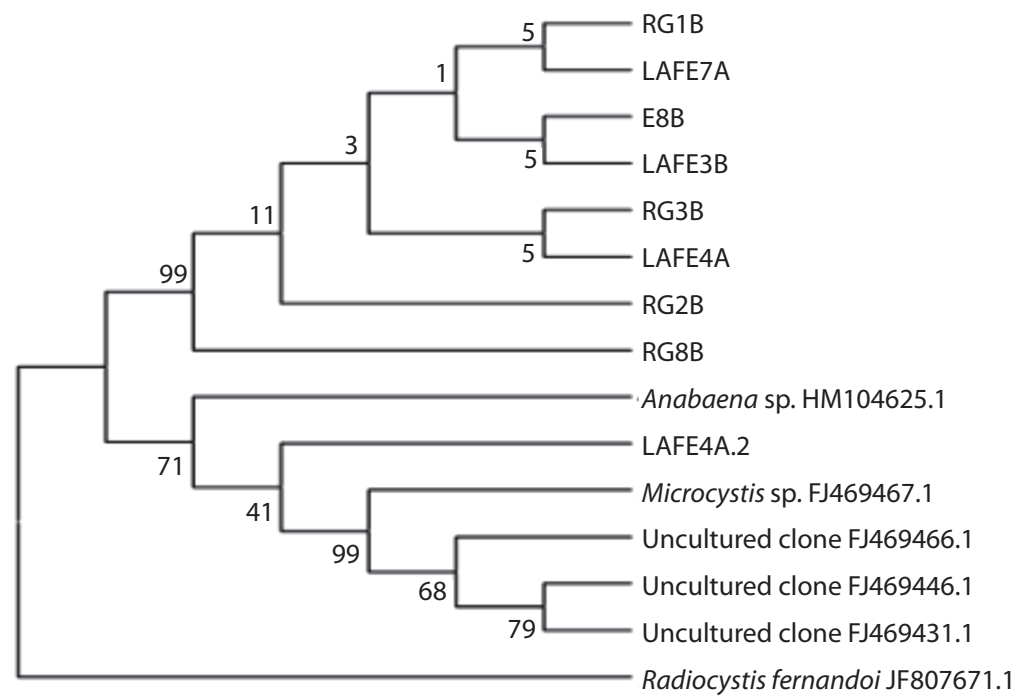

Fig. 1. Dendrograma de agrupamiento para las muestras amplificadas del gen mcyA, en los embalses Riogrande II y La Fe, Colombia. Método de agrupamiento por Máxima Verosimilitud (Maximum-likelihood), modelo de sustitución Kimura-2P (K2) y aproximación de Bootstrapping de 1000 permutaciones. RG: Embalse Riogrande II; LAFE: Embalse La Fe. Números después de la abreviatura del sitio son las estaciones dentro de cada embalse (ver Cuadro 1). Secuencias descargadas del GenBank y tomadas como outgroup (ver Cuadro 3): Anabaena sp. BIR259, No accesión HM104625.1; Microcystis sp. M124FF01, Nº accesión FJ469467.1; Uncultured bacterium clone M1089FF01, No accesión FJ469466.1; Uncultured bacterium clone M201FF02, No accesión FJ469431.1; Radiocystis fernandoi SPC 736, Nº accesión FJ807671.1. Números a la izquierda son los valores de Bootstrapping.

Fig. 1. Maximum-likelihood clustering dendrogram for PCR amplification of mcyA gene, of samples from Riogrande II and La Fe reservoirs, Colombia. Kimura-2P substitution model and bootstrapping permutations (1 000). RG: Riogrande II reservoir; LAFE: La Fe reservoir. Numbers in the abbreviation of sampling site names matches with the sampling stations within each reservoir (Table 1). Outgroup ADN sequences downloaded from GenBank (Table 3): Anabaena sp. BIR259, accession $\mathrm{N}^{\circ}$ HM104625.1; Microcystis sp. M124FF01, accession $\mathrm{N}^{\circ}$ FJ469467.1; Uncultured bacterium clone M1089FF01, accession N ${ }^{\circ}$ FJ469466.1; Uncultured bacterium clone M201FF02, accession No FJ469431.1; Radiocystis fernandoi SPC 736, accession $\mathrm{N}^{\circ}$ FJ807671.1. Numbers to the left are Bootstrapping values.

embalses Riogrande II y La Fe $(0-4 \%$ de las replicaciones del remuestreo), y tres de las 13 muestras de los embalses antioqueños tuvieron valores altos de bootstrapping (58-99\% de las replicaciones del remuestreo).

Evaluación de diversidad de cepas cianobacterianas en los embalses Riogrande II y La Fe:

Evaluación de la amplificación de secuencias de la subunidad 16S del ARN ribosomal (rRNA) y su evaluación en geles de poliacrilamida para la técnica DGGE: Para los embalses Riogrande II y $\mathrm{La} \mathrm{Fe}$, se obtuvieron amplificaciones de la región $359 \mathrm{~F}_{\mathrm{GC}}-781 \mathrm{~F}(\mathrm{a}, \mathrm{b})$ del gen $16 \mathrm{~S}$ del ARN ribosomal (rRNA), las cuales se corrieron en geles de poliacrilamida para la técnica DGGE. Las bandas obtenidas se pudieron visualizar mediante los protocolos de tinción con nitrato de plata (Fig. 3).

Análisis de los agrupamientos por patrones de bandeo de las reacciones obtenidas por amplificación y DGGE de la región 16S rRNA: Los geles de poliacrilamida digitalizados y analizados con el programa GelCompar II permitieron realizar agrupamientos de bandas comunes y no comunes en los embalses Riogrande II y La Fe. Se detectaron 35 bandas diferentes en las muestras del embalse Riogrande II, y 30 bandas diferentes para el embalse $\mathrm{La} \mathrm{Fe}$, con las cuales se realizó el dendrograma 


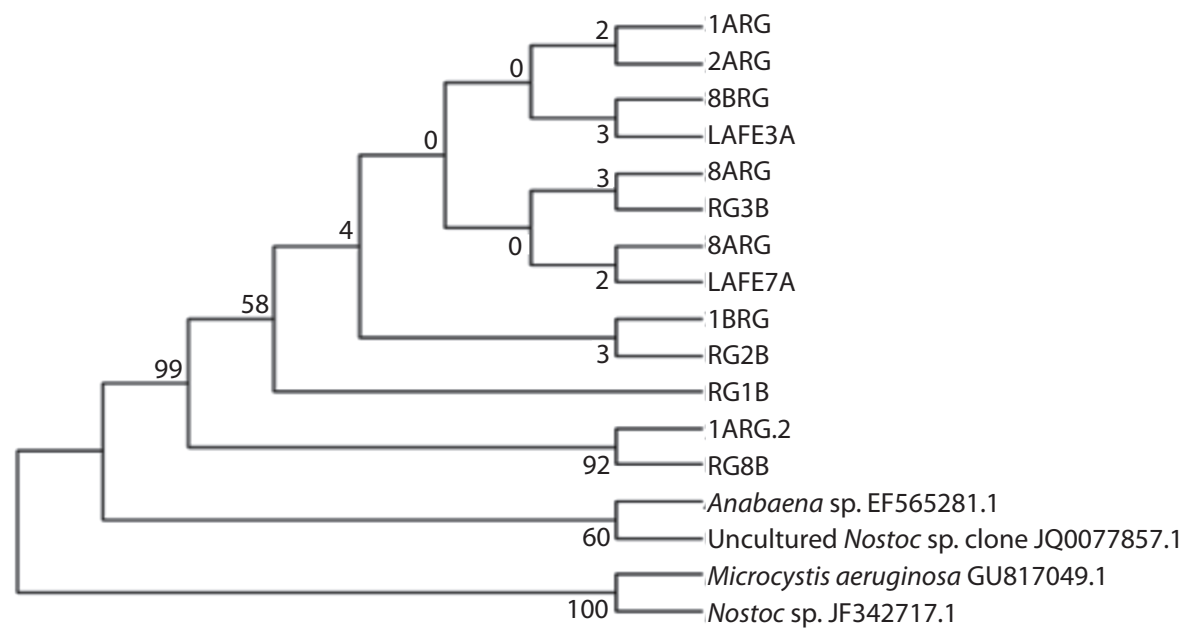

Fig. 2. Dendrograma de agrupamiento para las muestras amplificadas del gen $m c y$ E, en los embalses Riogrande II y La $\mathrm{Fe}$, Colombia. Método de agrupamiento por Máxima Verosimilitud (Maximum-likelihood), modelo de sustitución Kimura2P (K2) y aproximación de Bootstrapping de 1000 permutaciones. RG: Embalse Riogrande II; LAFE: Embalse La Fe. Números después de la abreviatura del sitio son las estaciones dentro de cada embalse (Cuadro 1). Secuencias descargadas del GenBank y tomadas como outgroup (Cuadro 3): Anabaena sp. BIR259, Nº accesión EF565281.1; Uncultured Nostoc sp. clone K S45, No accesión JQ007857.1; Microcystis aeruginosa BR12, $\mathrm{N}^{\circ}$ accesión GU817049.1; Nostoc sp. 74.2, $\mathrm{N}^{\circ}$ accesión JF342717.1. Números a la izquierda son los valores de Bootstrapping.

Fig. 2. Maximum-likelihood clustering dendrogram for PCR amplification of mcyE gene, of samples from Riogrande II and La Fe reservoirs, Colombia. Kimura-2P substitution model and bootstrapping permutations (1 000). RG: Riogrande II reservoir; LAFE: La Fe reservoir. Numbers in the abbreviation of sampling site names matches with the sampling stations within each reservoir (Table 1). Outgroup ADN sequences downloaded from GenBank (Table 3): Anabaena sp. BIR259, accession $\mathrm{N}^{\circ}$ EF565281.1; Uncultured Nostoc sp. clone K S45, accession No JQ007857.1; Microcystis aeruginosa BR12, accession $\mathrm{N}^{\circ}$ GU817049.1; Nostoc sp. 74.2, accession $\mathrm{N}^{\circ}$ JF342717.1. Numbers to the left are Bootstrapping values.

descripto de agrupaciones genéticas (Fig. 4). Se agruparon la mayoría de sitios de muestreo dentro de cada embalse a partir de los geles de poliacrilamida obtenidos. El dendrograma obtenido separa dos agrupaciones genéticas, diferenciando con claridad las muestras del embalse Riogrande II de las del embalse La Fe, exceptuando las muestras del sitio 7A. (Fig. 5).

\section{DISCUSIÓN}

En este proyecto, la mayoría de cebadores evaluados para amplificar regiones de ADN de interés, permitieron obtener resultados positivos en las muestras de agua de los embalses Riogrande II y La Fe, para genes que codifican para ficocianina de cianobacterias $\mathrm{y}$ algunos péptidos asociados con toxicidad (mcyA, mcyE). Así mismo, se obtuvo éxito en la amplificación de regiones del gen que codifica para la subunidad $16 \mathrm{~S}$ del ARN ribosomal (rRNA). Estos resultados son importantes debido a que son indicadores de la presencia de cepas de cianobacterias con potencial toxicidad en los embalses Riogrande II y La Fe, destinados para la potabilización de agua en centros urbanos de la ciudad de Medellín, Colombia.

La amplificación de fragmentos de la región $c p c$-IGS específica de cianobacterias en muestras de agua de embalses, puede dar una idea inicial de la presencia de cianobacterias. No obstante, su identificación en muestras de agua no permite determinar cuáles cepas o géneros de cianobacterias están presentes en las muestras evaluadas. Así mismo, con la amplificación de esta región no se logra diferenciar cepas tóxicas (Bittencourt-Oliveira et al., 2001). Sin embargo, los cebadores evaluados 


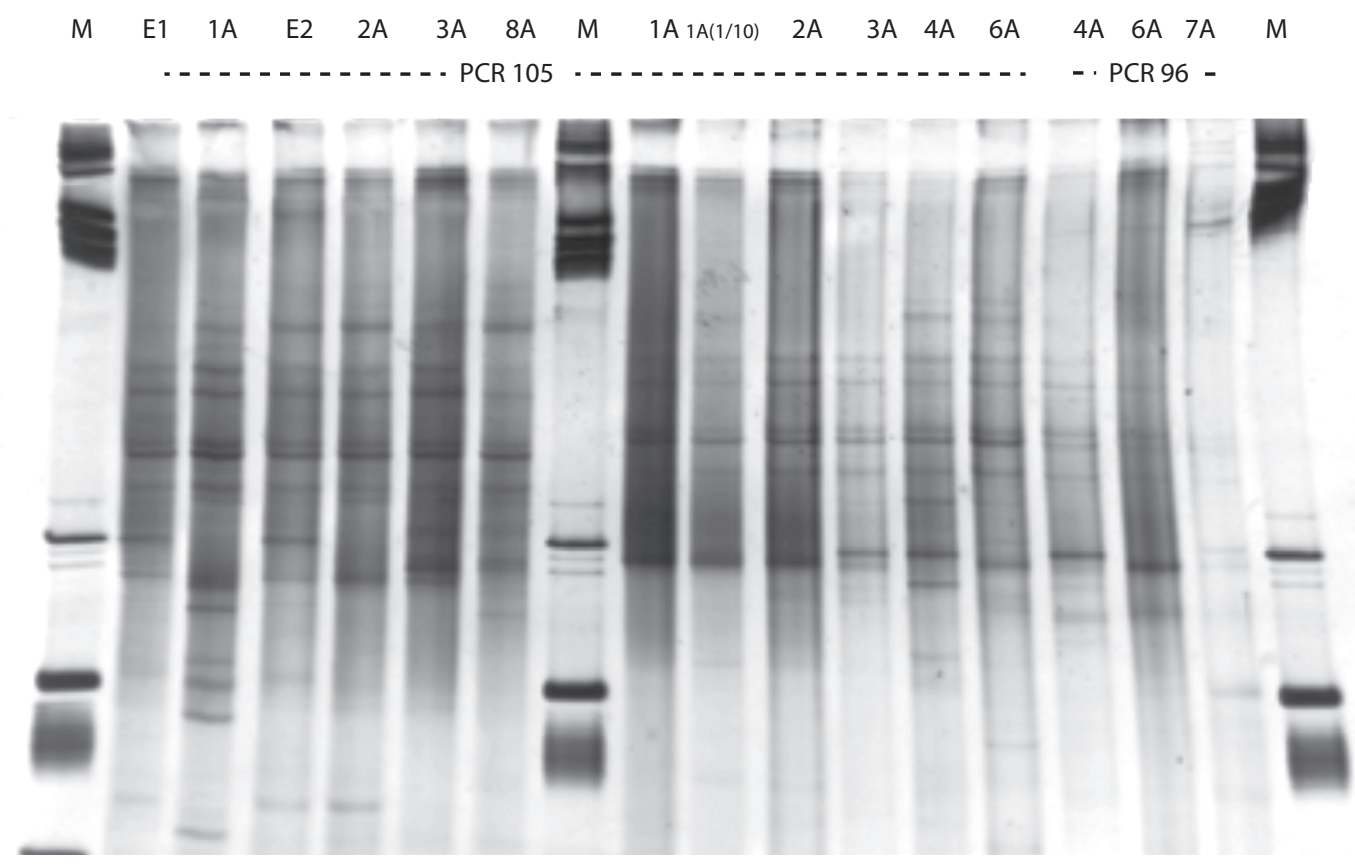

Fig. 3. Gel de poliacrilamida en gradientes desnaturalizantes de urea-formamida - DGGE, para la región 359F-GC/781R. Pozos E1-8A: Embalse Riogrande II; M: marcador de peso molecular (100pb); 1A-7A: Embalse La Fe.

Fig. 3. Urea-formamide denaturant gradient polyacrilamide gel (DGGE), of 359F-GC/781R 16S rRNA region. E1-8A wells: Riogrande II reservoir; M: DNA ladder (100bp); 1A-7A wells: La Fe reservoir.

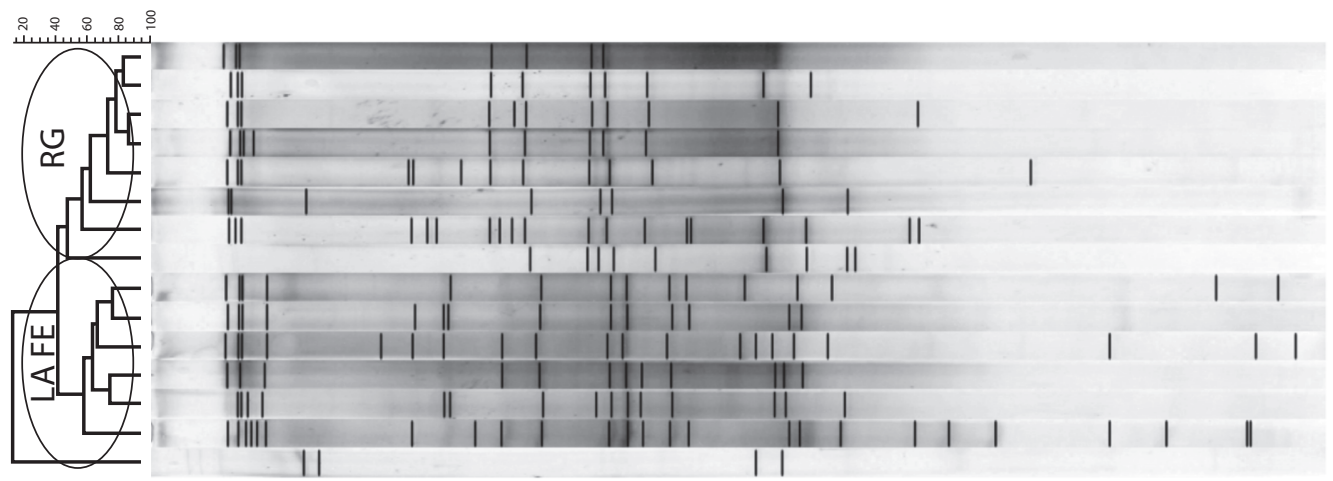

Fig. 4. Dendrograma UPGMA y patrones de bandeo obtenidos con la técnica DGGE y analizados con el programa GelCompar II, en diferentes muestras amplificadas del gen 16S del ARNr de los embalses Riogrande II y La Fe, Colombia. La Fe: Embalse La Fe; RG: Embalse Riogrande II.

Fig. 4. UPGMA dendrogram and banding patterns from DGGE technique, in 16S rRNA samples from Riogrande II and La Fe reservoirs, Colombia. La Fe: La Fe reservoir; RG: Riogrande II reservoir. 


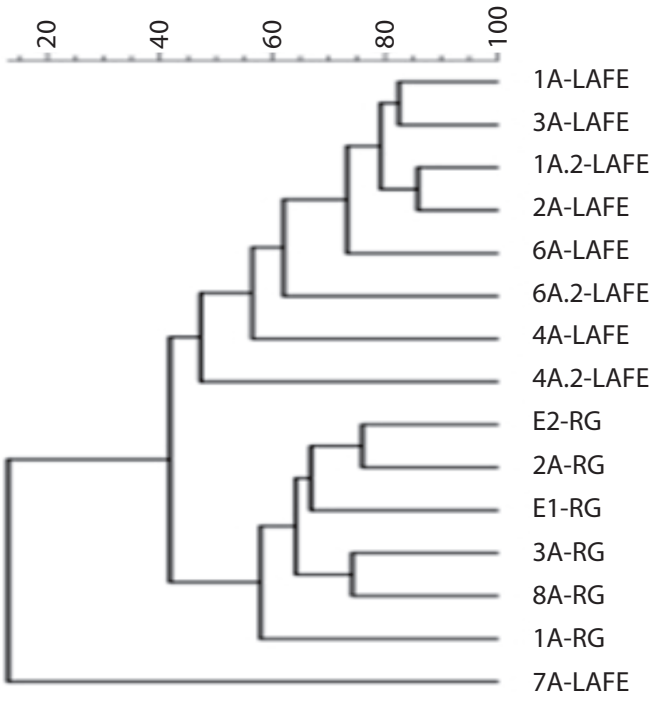

Fig. 5. Dendrograma obtenido con la evaluación de la técnica DGGE usando el algoritmo UPGMA y el coeficiente de similitud de Dice, en diferentes muestras amplificadas del gen 16S ARNr en los embalses Riogrande II y La Fe, Colombia. Los valores localizados en la parte superior del gráfico son los porcentajes de similitud (\%) entre muestras. LAFE: Embalse La Fe; RG: Embalse Riogrande II. Los números que aparecen antes de la abreviatura de cada embalse corresponden con las estaciones de muestreo dentro de cada embalse, descriptos en el cuadro 1.

Fig. 5. UPGMA-Dice similarity coefficient dendrogram in PCR-DGGE 16S rRNA samples from Riogrande II and La Fe reservoirs, Colombia. Values at the top of dendrogram are similarity percentages (\%) among samples. LAFE: La Fe reservoir; RG: Riogrande II reservoir. Numbers before abbreviations at each reservoir matches with sampling sites within reservoir, as seen in table 1.

para los genes relacionados con toxicidad $m c y \mathrm{~A}$ y $m c y \mathrm{E}$, ayudaron a detectar regiones relacionadas con cepas y géneros cianobacterianos como Microcystis con potencial toxicidad.

Los resultados de las amplificaciones inespecíficas de regiones del gen mcyA para muestras de agua de los embalses Riogrande II y La Fe eran de esperarse. La amplificación del gen mcyA solo apunta a describir la presencia de cepas potencialmente productoras de microcistinas sin discriminación de cepas o especies, lo cual ha sido relacionado en estudios anteriores (Hisbergues et al., 2003; Hotto et al., 2007). Esto es diferente de los resultados que pueden arrojar amplificaciones del gen $m c y \mathrm{E}$, el cual usa cebadores específicos de cepas y especies (Vaitomaa et al., 2003; Rantala et al., 2006). De esta forma, para la región $m c y \mathrm{E}$, también se encontró el género cianobacteriano Microcystis sp. a partir de la información de secuenciación contrastada en las bases de datos geneticos del NCBI, con representantes de dos cepas diferentes de $M$. aeruginosa para los dos embalses evaluados.

De acuerdo con los dendrogramas obtenidos para ambos genes, se indica un alto grado de similitud entre las mismas secuencias y poca divergencia genética, para las secuencias de los dos genes evaluados en los embalses antioqueños $(m c y \mathrm{~A}, m c y \mathrm{E})$. Estos datos indican a su vez alta similitud genética entre la mayoría de secuencias analizadas en este trabajo, en dos embalses antioqueños separados geográficamente por menos de $50 \mathrm{~km}$ linealmente y por $90 \mathrm{~km}$ de carretera. Por otra parte, la mayoría de las secuencias de cianobacterias de diferentes ecosistemas y latitudes descargadas de la página del NCBI, tuvieron altos valores de remuestreo por bootstrapping entre sí. Por estas razones, estas secuencias fueron de utilidad como outgroups para las amplificaciones de los dos genes de toxicidad evaluados. Para el gen $m c y$ A, el dato más sorprendente se relaciona con la ubicación de una secuencia del embalse La Fe (LAFE4A), en el agrupamiento de secuencias del NCBI. No obstante y como ya se ha mencionado, la amplificación de esta región para la mayoría de estudios relacionados ha mostrado un alto grado de inespecificidad debido a que el gen que codifica para la subunidad A del cluster que codifica para el heptapéptido hepatotóxico microcistina-LR, está presente en diversas clases de cianobacterias productoras de microcistinas (Hisbergues et al., 2003). Es posible que la secuencia del embalse La Fe hallada dentro de la agrupación tomada como outgroup, difiera del resto de secuencias encontradas en los embalses antioqueños, por motivos relacionados con aspectos de la cuenca que hayan permitido que se mantengan cepas diferentes en cada sitio de muestreo dentro de cada embalse. Por otra parte, para el gen $m c y \mathrm{E}$ los análisis obtenidos de alinear secuencias de 
los embalses antioqueños con secuencias del NCBI de diferentes ecosistemas en una escala mundial, fueron más contundentes para separar las muestras secuenciadas de los embalses Riogrande II y La Fe. Aunque las cepas relacionadas en este estudio sean similares a cepas descriptas en otros países, cabe mencionar que los dos embalses evaluados en Antioquia son relativamente nuevos (aproximadamente 25 años para Riogrande II y 40 años para La Fe) y relativamente cercanos como ya se describió, lo cual podría explicar la alta similitud entre secuencias entre ambos ecosistemas.

Parte de los resultados del presente estudio confirman datos publicados por Correa en 2008 para el embalse Riogrande II. Este autor mostró que para el embalse Riogrande II se encontraban por taxonomía clásica tres géneros de cianobacterias con potencial producción de la toxina Microcistina-LR: Microcystis aeruginosa, M. wesenbergii, Anabaena sp. y Radiocystis sp. en diversos eventos de florecimientos de cianobacterias (Correa, 2008). Pese a lo anterior, la presencia de Radiocystis debería confirmarse en evaluaciones futuras de toxicidad y diversidad cianobacterianas en el embalse Riogrande II, dado que su presencia se ha limitado principalmente a estudios llevados a cabo en el Brasil. Es importante enfatizar el hecho de encontrar dos cepas diferentes de Microcystis en muestras de agua evaluadas para el gen $m c y \mathrm{E}$ en el embalse La Fe, puesto que es un sitio que en los últimos años no ha tenido problemas de presencia de factores que desencadenen problemas de eutrofización (Palacio, com. pers.). De esta forma, en el presente trabajo pudo detectarse la presencia de genes de toxicidad de cianobacterias, sin evidencias visibles de eventos de florecimientos masivos de cianobacterias potencialmente tóxicas, para los embalses Riogrande II y La Fe. Sin embargo, aunque en este trabajo no se cuenta con datos de mediciones de parámetros físico-químicos de las estaciones de muestreo, es importante la detección inicial de secuencias de genes asociados con toxinas de cianobacterias en embalses de importancia para potabilización de agua.
Las evaluaciones microscópicas de cianobacterias son lábiles a errorres en la identificación de taxones, lo cual depende en gran medida de la experiencia del investigador. Por ello, la caracterización molecular de comunidades cinaobacterianas usando secuencias parciales de la subunidad $16 \mathrm{~S}$ del ARN ribosomal, puede ser una herramienta complementaria para la identificación de microorganismos que prevalecen en un hábitat en particular (Dadheech, Krienitz, Kotut, Ballot \& Casper, 2009). De acuerdo con esta idea, los resultados obtenidos por DGGE (Electroforesis en Geles con Gradiente Desnaturalizante) pueden proporcionar una separación visual de la mezcla de $\mathrm{ADN}$ en las muestras (fingerprinting, huellas genéticas) en función del polimorfismo en las secuencias, sin necesidad de usar enzimas de restricción (Romaní, Artigas, Camacho, Graça \& Pascoal, 2009).

En el presente trabajo, aunque se amplificaron la mayoría de muestras para los dos fragmentos evaluados de la subunidad 16S rRNA, no fue posible reamplificar las eluciones de ADN de bandas obtenidas de geles de poliacrilamida. No obstante, se hallaron asociaciones de las muestras amplificadas de la region 359781 de este gen en los embalses Riogrande II y La Fe. Dado que en varios estudios de cianobacterias de muestras ambientales se han hallado diferencias en las cepas encontradas con potencial toxicidad (Dos Anjos et al., 2006; Rantala et al., 2006; Magana-Arachchi, Wanigatunge \& Jeyanandarajah, 2008), es factible que se encuentren diferencias entre las cepas encontradas en este estudio.

En otros estudios, se han realizado análisis similares a partir de la información obtenida por los patrones de bandeo de geles de poliacrilamida en gradientes desnaturalizantes de urea y formamida, para la evaluación de diversidad molecular de la región 359-781 del gen 16S del ARN ribosomal (rRNA) de cianobacterias en ecosistemas de aguas continentales. En 2009, Dadheech y colaboradores, evaluaron la diversidad de cepas de cianobacterias en sedimentos y agua de varios lagos africanos, mediante perfiles de DGGE. Para cada ecosistema evaluado, 
encontraron entre 5-11 bandas para cada perfil. El patrón de bandeo obtenido de DGGE fue similar entre réplicas de las muestras. Así mismo, el análisis de cluster del dendrograma mediante el algoritmo UPGMA mostró cuatro agrupaciones principales, de las cuales algunas agrupaciones eran compartidas por muestras de varios lagos (Dadheech et al., 2009). Por su parte, en 2008 Dorador y colaboradores evaluaron la diversidad de cianobacterias en humedales salinos en el norte de Chile. Estos investigadores encontraron patrones de DGGE de entre 5 y 11 bandas en muestras de agua, y entre 9-14 patrones de bandas de DGGE en muestras de sedimentos, lo cual pudo utilizarse como indicadores de riqueza de especies. Estos datos revelaron una habilidad mejorada para la detección de cianobacterias usando métodos moleculares, al contrastar esta técnica con técnicas de detección de la taxonomía tradicional (Dorador, Vila, Imhoff \& Witzel, 2008).

Para el presente trabajo, es importante resaltar que fue posible la detección de un alto número de bandas para los ecosistemas evaluados, lo que lo destaca al compararse con los otros estudios mencionados (Riogrande II, 35 bandas diferentes; La Fe, 30 bandas diferentes). Con relación a la reamplificación de las bandas eluídas de DGGE, es claro que no en todos los casos se pueden obtener secuencias de las bandas escogidas para evaluaciones de diversidad, tal y como sucedió en este estudio. Sin embargo, en el caso de tener éxito en la reamplificación de muestras de bandas de DGGE, es preciso mencionar que se puede contar con información de secuencias idénticas de bandas diferentes dentro de la misma población analizada (Boutte, Grubisic, Balthasart \& Wilmotte, 2006). Esto puede suceder debido a que amplicones dominantes podrían distribuirse en posiciones diferentes dentro del mismo patrón de bandeo, probablemente porque varios dominios tienen propiedades bioquímicas similares, siendo lábiles a efectos estocásticos que podrían causar que un dominio se desnaturalice antes que otros (Nikolausz, Sipos, Revesz, Szekely \& Marialigeti, 2005; Boutte et al., 2006). Independientemente de la imposibilidad de re-amplificar secuencias de la subunidad $16 \mathrm{~S}$ rRNA, en este trabajo fue posible determinar el grado de similitud entre los hallazgos obtenidos en cada embalse, de acuerdo con las agrupaciones obtenidas por el programa de análisis de bandas GelCompar II. Este análisis genético permitió determinar la utilidad de la técnica DGGE, para el hallazgo de perfiles genéticos únicos para cada ecosistema evaluado.

Aunque este trabajo es de carácter informativo de la presencia o ausencia de cepas de cianobacterias con potencial toxicidad, es recomendable incluir información de carácter físico-químico y ambiental de los sitios de muestreo para correlacionar dichas evaluaciones con los datos obtenidos de amplificación de regiones de toxicidad en diferentes épocas del año en los embalses Riogrande II y La Fe. Así mismo, puede recomendarse para futuros trabajos la detección del número de copias de genes y su expresión por qPCR (Quantitative real-time $P C R$, PCR cuantitativa en tiempo real) de los diferentes genes que hacen parte del cluster $m c y$, algunos de ellos que codifican para péptidos involucrados con la potencial toxicidad de cepas de cianobacterias productoras de microcistinas (Ngwa, Madramootoo \& Jabaji, 2012).

Por último, se podrían llevar a cabo evaluaciones adicionales de diversidad de cepas y géneros de cianobacterias en los embalses Riogrande II y La Fe, mediante reamplificación de bandas obtenidas por la técnica DGGE, o mediante la secuenciación de regiones del gen $16 \mathrm{~S}$ en una aproximación de metagenomas. De esta forma, los métodos moleculares independientes de cultivos cianobacterianos, relacionados con extracción de ADN directamente de muestras ambientales, se están haciendo más comunes como formas de estudiar microorganismos provenientes de ecosistemas complejos con problemas de eutrofización (Pope \& Patel, 2008). Estos trabajos pueden ser de gran utilidad para estimar la posible relación entre la presencia de diversas cepas de cianobacterias con las condiciones ambientales, y para determinar posibles relaciones evolutivas entre cepas presentes en el mismo ecosistema. Por 
su condición de procariotes y por los eventos de eutrofización artificial que se pueden presentar en estos ecosistemas, puede ser interesante estudiar la capacidad de evolución de las cepas de cianobacterias en términos de diferencias en las tasas de mutación y/o sustitución nucleotídica de secuencia específicas, lo cual puede ser indicador a su vez de su capacidad de adaptación a estos ecosistemas artificiales. Estudios adicionales de la diversidad molecular de cianobacterias tóxicas podrían incluir el uso de estas herramientas de la biología molecular y de la bioinformática, siendo de utilidad en el apoyo de estudios limnológicos para la detección espacial o temporal de estos microorganismos, lo cual puede ser a su vez una herramienta nueva para la toma de decisiones en plantas de potabilización de agua.

\section{AGRADECIMIENTOS}

A la DIME - Dirección de Investigaciones de la Universidad Nacional de Colombia Sede Medellín, por la financiación del presente estudio, derivado del proyecto "Desarrollo de bioensayos para la detección de toxinas de cianobacterias", Código 20201007168. A Jaime Palacio y Néstor Aguirre del Grupo GAIA de la Universidad de Antioquia, por su colaboración en la obtención de las muestras de agua utilizadas en este estudio. Al Laboratorio de Biología Molecular y Celular de la Universidad Nacional de Colombia Sede Medellín, por el uso de sus instalaciones y equipos para el componente de biología molecular. A Mónica Higuita, Claudia Moreno y Sebastián Reynaldi, de la Universidad Nacional de Colombia Sede Medellín, por su colaboración en los análisis de datos moleculares, por la asesoría en la técnica DGGE, y por su ayuda inicial en la escritura del proyecto y la consecución de recursos para el desarrollo de este trabajo, respectivamente.

\section{RESUMEN}

En embalses, la eutrofización es consecuencia de procesos naturales y de actividades humanas, lo cual puede facilitar la aparición de afloramientos de cianobacterias potencialmente tóxicas. En este trabajo, se utilizaron dos técnicas moleculares en la detección de genes presentes en cepas potencialmente tóxicas de cianobacterias y evaluaciones de diversidad molecular de cianobacterias en los embalses para potabilización de agua, Riogrande II y La $\mathrm{Fe}$, Colombia. Entre 2010-2011, se tomaron 12 muestras de agua en ambos embalses y se realizaron extracciones de ADN para un análisis de marcadores moleculares mediante PCR y DGGE. Se amplificaron secuencias entre 250-300pb de los genes mcyA y mcyE, implicados en la toxicidad de cepas de cianobacterias. Asimismo, se amplificaron secuencias de la región $16 \mathrm{~S}$ del ARN ribosomal (422pb), para la técnica DGGE. Se corrieron geles de poliacrilamida en gradientes de desnaturalización, se realizó agrupamiento genético (UPGMA), y se separaron por patrones de bandeo las muestras de cada embalse evaluado. Se demuestra la utilidad de las técnicas moleculares en estudios relacionados con la búsqueda de genes asociados con toxicidad y diversidad molecular de cianobacterias en muestras de agua provenientes de embalses de agua con fines de potabilización para centros urbanos.

Palabras clave: eutrofización, cianobacterias, toxicidad, microcistinas, diversidad, marcadores moleculares.

\section{REFERENCIAS}

Abuchaibe, H., Agudelo, J., \& Sañudo, C. (1998). Descripción general de las instalaciones del acueducto metropolitano. Revista Empresas Públicas de Medellin, 10, 35-97.

Azevedo, S. M. F. O. \& Carmouze, J. (1994). Une mortalité de poissons dans une lagune tropicale (Brésil) durant une période de dominance de cyanophyceae. Coincidence ou conséquence?. Revue d'Hydrobiologie Tropicale, 27, 265-272.

Azevedo, S. M., Carmichael, W. W., Jochimsen, E. M., Rinehart, K. L., Lau, S., Shaw, G. R., \& Eaglesham, G. K. (2002). Human intoxication by microcystins during renal dialysis treatment in Caruaru-Brazil. Toxicology, 181-182, 441-446.

Bittencourt-Oliveira, M. C., Oliveira, M. C., \& Bolch, C. J. S. (2001). Genetic variability of some Brazilian strains of Microcystis aeruginosa complex (Cyanophyceae/Cyanobacteria) using the nucleotide sequence analysis of the intergenic spacer and flanking regions from $c p c$ BA-phycocyanin operon. Journal of Phyco$\log y, 37,810-818$.

Boutte, C., Grubisic, S., Balthasart, P., \& Wilmotte, A. (2006). Testing of primers for the study of cyanobacterial molecular diversity by DGGE. Journal of Microbiological Methods, 65, 542-550.

Carmichael, W. W., Azevedo, S. M. F. O., An, J. S., Molica, R. J. R., Jochimsen, E. M., Lau, S., Rinehart, K. L., Shaw, G. R., \& Eaglesham, G. K. (2001). Human 
fatalities from cyanobacteria: chemical and biological evidence for cyanotoxins. Environmental Health Perspectives, 109, 663-668.

Codd, G. A., Steffensen, D. A., Burch, M. D., \& Baker, P. D. (1994). Toxic blooms of cyanobacteria in Lake Alexandrina, South Australia - learning from history. Australian Journal of Marine and Freshwater Research, 45, 731-736.

Corporación Autónoma Regional del Centro de Antioquia - CORANTIOQUIA. (1997). Conservación, ordenamiento y manejo del sistema de páramos y bosques altoandinos del noroccidente medio antioqueño. (Tomo I: Diagnóstico biofísico, socio-económico y socio-cultural). Corantioquia, Medellín, Colombia.

Correa, I. (2008). Toxicidad de florecimientos de cianobacterias en el embalse Riogrande II. (Tesis de maestría). Universidad de Antioquia, Medellín, Colombia.

Dadheech, P. K., Krienitz, L., Kotut, K., Ballot, A., \& Casper, P. (2009). Molecular detection of uncultured cyanobacteria and aminotransferase domains for cyanotoxin production in sediments of different Kenyan lakes. FEMS Microbiology Ecology, 68, 340-350.

Departamento Administrativo Nacional de Estadística DANE. (2005). Censo General 2005, Nivel Nacional. Bogotá, Colombia.

Dawson, R. M. (1998). The toxicology of microcystins. Toxicon, 36(7), 953-962.

Domingos, P., Rubim, T. K., Molica, R. J. R., Azevedo, S. M. F. O., \& Carmichael, W. W. (1999). First report of microcystin production by picoplanktonic cyanobacteria isolated from a northeast Brazilian drinking water supply. Environmental Toxicology, 14, 31-35.

Dorador, C., Vila, I., Imhoff, J., \& Witzel, K. P. (2008). Cyanobacterial diversity in Salar de Huasco, a high altitude saline wetland in northern Chile: an example of geographical dispersion? FEMS Microbiology Ecology, 64, 419-432.

Dos Anjos, M., Bittencourt-Oliveira, M., Zajac, M., Hiller, S., Christian, B., Erler, K., Luckas, B., \& Pinto, E. (2006). Detection of harmful cyanobacteria and their toxins by both PCR amplification and LC-MS during a bloom event. Toxicon, 48, 239-45.

Fewer, D. P., Halinen, K., Sipari, H., Bernardová, K., Mänttäri, M., Eronen, E., \& Sivonen, K. (2011). Nonautonomous transposable elements associated with inactivation of microcystin gene clusters in strains of the genus Anabaena isolated from the Baltic Sea. Environmental Microbiology Reports, 3(2), 189-194.

Gaevsky, N. A., Kolmakov, V. I., Belykh, O. I., Tikhonova, I. V., Joung, Y., Ahn, T. S., Nabatova, V. A., \& Gladkikh, A. S. (2011). Ecological development and genetic diversity of Microcystis aeruginosa from artificial reservoir in Russia. The Journal of Microbiology, 49(5), 714-720.
Gehringer, M. M., Adler, L., Roberts, A. A., Moffitt, M. C., Mihali, T. K., Mills, T. J., Fieker, C., \& Neilan, B. A. (2012). Nodularin, a cyanobacterial toxin, is synthesized in planta by symbiotic Nostoc sp. The ISME Journal, 6(10), 1834-1847.

Genuário, D. B., Silva-Stenico, M. E., Welker, M., Moraesc, L. A., \& Fiore, M. F. (2010). Characterization of a microcystin and detection of microcystin synthetase genes from a Brazilian isolate of Nostoc. Toxicon, 55, 846-854.

Havens, K. E., James, R. T., East, T. L., \& Smith, V. H. (2003). N:P ratios, light limitation, and cyanobacterial dominance in a subtropical lake impacted by non-point source nutrient pollution. Environmental Pollution, 122(3), 379-90.

Hisbergues, M., Christiansen, G., Rouhiainen, L., Sivonen, K., \& Börner, T. (2003). PCR-based identification of microcystin-producing genotypes of different cyanobacterial genera. Archives of Microbiology, 180, 402-410.

Hitzfeld, B. C., Hoger, S. J., \& Dietrich, D. R. (2000). Cyanobacterial toxins: removal during drinking water treatment, and human risk assessment. Environmental Health Perspectives, 108(1), 113-122.

Jochimsen, E. M., Carmichael, W. W., An, J., Cardo, D., Cookson, S. T., Holmes, C. E. M., \& Jarvis, W. R. (1998). Liver failure and death following exposure to microcystin toxins at a hemodialysis center in Brazil. The New England Journal of Medicine, 36, 373-378.

Hall, T.A. 1999. Bioedit. A user friendly biological sequence aligment editor and analysis program for windows 95/98/NT. Nucleic Acids Symposium Series 41: 95-98.

Hotto, A. M., Satchwell, M. F., \& Boyer, G. L. (2007). Molecular characterization of potential microcystinproducing cyanobacteria in Lake Ontario embayments and nearshore waters. Applied and Environmental Microbiology, 73(14), 4570-4578.

Kaasalainen, U., Fewer, D. P., Jokela, J., Wahlsten, M., Sivonen, K., \& Rikkinen, J. (2012). Cyanobacteria produce a high variety of hepatotoxic peptides in lichen simbiosis. Proceedings of the National Academy of Sciences of the United States of America, 109(15), 5886-5891.

Lorenzi, A. S., Andreote, F. D., Furtado, A. L., Agujaro, L. F., Machado, J. B., Figueira, A., \& Fiore, M. F. (s.f.). Development and field testing of a LUX real-time PCR for quantification of Microcystis and potential microcystin producers. Recuperado de http://www. ncbi.nlm.nih.gov/nuccore/FJ807671.1

Magana-Arachchi, D., Wanigatunge, R., \& Jeyanandarajah, P. (2008). Setting up a polymerase chain reaction assay for the detection of toxic cyanobacteria. Journal of the National Science Foundation of Sri Lanka, 36(3), 229-233. 
Matsunaga, T., Takeyama, H. \& Nakayama, H. (2001). $16 \mathrm{~S}$ rRNA-Targeted identification of cyanobacterial genera using oligonucleotide-probes immobilized on bacterial magnetic particles. Journal of Applied Phycology, 13, 389-394.

Moisander, P. H., Lehman, P. W., Ochiai, M., \& Corum, S. (2009). Diversity of Microcystis aeruginosa in the Klamath River and San Francisco Bay delta, California, USA. Aquatic Microbial Ecology, 57, 19-31.

Montoya, Y. \& Ramírez, J. J. (2007). Flujos de mineralización en el embalse tropical Río Grande II (Antioquia, Colombia). Limnetica, 26(1), 39-51.

Muyzer, G., De Waal, E. C., \& Uitterlinden, A. G. (1993). Profiling of complex microbial populations by denaturing gradient gel electrophoresis analysis of polymerase chain reaction amplified genes coding for $16 \mathrm{~S}$ rRNA. Applied and Environmental Microbiology, 59(3), 695-700.

Nei, M. \& Li, W. H. (1979). Mathematical models for studying genetic variation in terms of restriction endonucleases. Proceedings of the National Academy of Sciences of the United States of America, 76(10), 5269-5273.

Neilan, B., Jacobs, D., \& Goodman, A. (1995). Genetic diversity and phylogeny of toxic cyanobacteria determined by DNA polymorphisms within the phycocyanin locus. Applied and Environmental Microbiology, 61, 3875-3883

Ngwa, F., Madramootoo, C., \& Jabaji, S. (2012). Monitoring toxigenic Microcystis strains in the Missisquoi bay, Quebec, by PCR targeting multiple toxic gene loci. Environmental Toxicology. doi: 10.1002/ tox. 21770

Nikolausz, M., Sipos, R., Revesz, S., Szekely, A., \& Marialigeti, K. (2005). Observation of bias associated with re-amplification of DNA isolated from denaturing gels. FEMS Microbiology Letters, 244, 385-390.

Nübel, U., Garcia-Pichel, F., \& Muyzer, G. (1997). PCR primers to amplify $16 \mathrm{~S}$ rRNA genes from cyanobacteria. Applied and Environmental Microbiology, 63(8), 3327-3332.

Otaya, L., Vásquez, G., \& Bustamante, G. (2008). Estimación de la oferta hídrica con información escasa en ecosistemas estratégicos. Revista Facultad Nacional de Agronomía Medellín, 61(1), 4366-4380.

Ouellette, A., Handy, S., \& Wilhelm, S. (2006). Toxic microcystis is widespread in Lake Erie: PCR detection of toxin genes and molecular characterization of associated cyanobacterial communities. Microbial Ecology, 51, 154-165.

Pope, P. B. \& Patel, B. K. C. (2008). Metagenomic analysis of a freshwater toxic cyanobacteria bloom. FEMS Microbiology Ecology, 64, 9-27.
Rademaker, J. L. W. \& de Bruijn, F. J. (2004). Computerassisted analysis of molecular fingerprint profiles and database construction. In G. A. Kowalchuk, F. J. De Bruijn, I. M. Head, A. D. L. Akkermans, \& J. D. Van Elsas (Eds.), Molecular Microbial Ecology Manual (pp. 1397-1446). Dordrecht, Nederlands: Springer.

Ramírez, J. J., Gutiérrez, F. L., \& Vargas, A. (2005). Respuesta de la comunidad fitoplanctónica a experimentos de eutrofización artificial realizados en la represa La Fe, El Retiro, Antioquia, Colombia. Caldasia, 27(1), 103-115.

Rantala, A., Rajaniemi-Wacklin, P., Lyra, C., Lepisto, L., Rintala, J., Mankiewicz-Boczek, J., \& Sivonen, K. (2006). Detection of microcystin-producing cyanobacteria in Finnish Lakes with genus-specific microcystin synthetase gene E $(m c y E)$ PCR and associations with environmental factors. Applied and Environmental Microbiology, 72(9), 6101-6110.

Rodger, H. D., Turnbull, T., Edwards, C., \& Codd, G. A. (1994). Cyanobacterial (blue-green-algal) bloom associated pathology in brown trout Salmo trutta L. in Loch Leven, Scotland. Journal of Fish Diseases, 17, 177-181.

Romaní, A., Artigas, J., Camacho, A., Graça, M., \& Pascoal, C. (2009). La biota de los ríos: los microorganismos heterotróficos. In Conceptos y técnicas en ecología fluvial. España: Fundación BBVA.

Runnegar, M. T., Kong, S., \& Berndt, N. (1993). Protein phosphatase inhibition and in vivo hepatotoxicity of microcystins. The American Journal of Physiology, 265(2), G224-30.

Sanguinetti, C. J., Dias Neto, E., \& Simpson, A. J. G. (1994). Rapid silver staining and recovery of PCR products separated on polyacrylamide gels. Biotechniques, 17, 915-919.

Tamura, K., Peterson, D., Peterson, N., Stecher, G., Nei, M., \& Kumar, S. (2011). MEGA5: Molecular Evolutionary Genetics Analysis using Maximum Likelihood, Evolutionary Distance, and Maximum Parsimony Methods. Molecular Biology and Evolution, 28, 2731-2739.

Tencalla, F. \& Dietrich, D. (1997). Biochemical characterization of microcystin toxicity in rainbow trout (Oncorhynchus mykiss). Toxicon, 35, 583-595.

Vaitomaa, J., Rantala, A., Halinen, K., Rouhiainen, L., Tallberg, P., Mokelke, L., \& Sivonen, K. (2003). Quantitative real-time PCR for determination of microcystin synthetase E copy numbers for Microcystis and Anabaena in lakes. Applied and Environmental Microbiology, 69, 7289-7297.

World Health Organization - WHO. (2004). Guidelines for drinking-water quality. Geneva, Switzerland: World Health Organization. 
